\title{
DESCRIPTION OF METHOD USED BY SAPIENZA UNIVERSITY IN ROME TO DELIVER REHABILITATION PROGRAM E-COURSES TO STUDENTS FOLLOWING THE COVID-19 EMERGENCY
}

\author{
Anna Berardi ${ }^{1}$, Marco Tofani ${ }^{2}$, Giovanni Galeoto ${ }^{2}$, Maria Auxiliadora Marquez ${ }^{3}$ \\ and Donatella Valente ${ }^{1}$ \\ ${ }^{1}$ Department of Human Neurosciences, Sapienza University of Rome, Viale dell'Università 30, 00185, Rome, Italy \\ ${ }^{2}$ Department of Public Health and Infection disease, Sapienza University of Rome, Piazzale Aldo Moro,5, 00185, \\ Rome, Italy \\ ${ }^{3}$ Paraplegic Center of Ostia, Rome, Italy, Viale Vega, 3, 00122 Lido di Ostia, Rome, Italy
}

\begin{abstract}
Most governments around the world have temporarily closed educational institutions in an attempt to contain the spread of the coronavirus disease 2019 (COVID-19). In Italy, teaching activities were suspended on March 5, 2020 based on provisions from competent authorities. Sapienza University in Rome has addressed the COVID-19 emergency by putting available tools in place to support remote teaching. The purpose of this paper is to describe and share the method used for the degree courses in the rehabilitation health program at Sapienza University in Rome to deliver courses to their students. The provision of distance learning was divided into three phases: (1) Activation of the teacher-student work environment (virtual class) using Google Classroom; (2) Publication on the teacher's webpage; (3) Teaching provision using Google Classroom or Google Meet. By March 11, 2020, all courses were created and access codes were communicated to the students, and to date several students are successfully attending the courses. In the academic world, sharing experiences is extremely important and necessary to achieve higher standards in education.
\end{abstract}

\section{KEYWORDS}

COVID-19, e-Learning, Examination, Universities

\section{INTRODUCTION}

Since March 11, 2020, when the World Health Organization (WHO) declared the coronavirus disease 2019 (COVID-19) to be a pandemic, most governments around the world have temporarily closed educational institutions in an attempt to contain the spread of COVID-19 (WHO, 2020). These nationwide closures are impacting over $90 \%$ of the world's student population (UNESCO, 2020a).

Normally, March is one of the busiest months in the academic calendar; even with buildings in lockdown and staff barred from their offices, learning goes on, displaced, but not discontinued. This year, COVID-19 is challenging the ability of the academic world to adapt and be resilient, and the education sector is responding to quarantine with a sudden shift to online learning (Electronic Platform for Adult Learning in Europe, 2020). In many respects, COVID-19 is drawing out the best from staff, who are committed to ensuring the education and wellbeing of all students is maintained. (Jones S., 2020)

In Italy, teaching activities were suspended on March 5, 2020 based on provisions of competent authorities (Decree of the President of the Council of Ministers, March 4, 2020) in response to the COVID-19 emergency. Sapienza, like all Italian universities, adopted the provisions of the government to confront the COVID-19 emergency. In this context, everything that followed was done with the dual objective of protecting the health of the country's citizens and guaranteeing the continuity of the university's activities. Sapienza faced the COVID-19 emergency by putting available tools in place to support educating by teachers and learning by students. In particular, in the unique circumstances caused by the pandemic, the university has begun delivering distance lessons by using the tools and training aids already available to the university community. The map 
of all useful tools and information for teachers and students accessible on the university website is available in the United Nations Educational (UNESCO) document (UNESCO, 2020b). The reorganization of remote activities for degree courses is under the coordination and control of the Presidents of the courses, to ensure proper planning of the lessons, clear communication to the students, and full monitoring of the process. The purpose of this paper is to describe and share the method used to deliver degree courses for the health profession's rehabilitation program at Sapienza University in Rome to its students.

\section{BODY OF PAPER}

Administrators of the degree courses for occupational therapy, speech therapy, physiotherapy, podiatry, orthoptics and ophthalmological assistance, psychiatric rehabilitation technique and therapy of neuro-psychomotricity of developmental age followed a common line to face the emergency. The courses were created by professionals who was already experienced in managing online courses (Farina, 2019; Paterniani, 2019; Galeoto, 2019a; Galeoto, 2019b). The provision of distance learning was divided into three phases:

Phase 1 - Activation of the teacher-student work environment (virtual class)

The course director activated the teacher-student work environment to deliver lessons remotely by using the functionality of Google Classroom for creating a virtual classroom, sharing teaching materials, and engaging in direct communication (chat/forum) with students. It was necessary to access the mailbox with @ uniroma1 university credentials and to access Classroom through the square icon in the icon menu (Figure 1). Each course in Google Classroom corresponds to a single teaching unit from the teacher. At the first authentication, it is necessary to click on the + symbol at the top right (Create your first course or Register) by selecting the Create Class item (Figure 2).

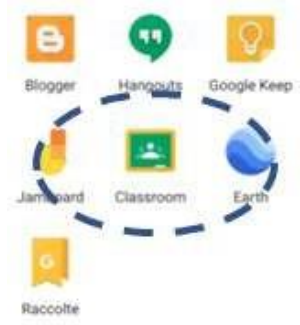

Figure 1. Classroom icon on Google

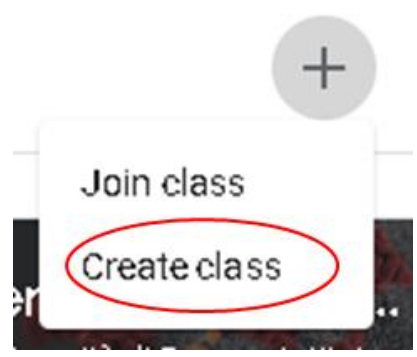

Figure 2. To create a class, click on the + symbol at the top right

Once the course is created, it will appear as shown in Figure 3. At this time, the teacher can share material with students in the Stream section, assign tasks and quizzes in the Classwork section, and view the list of enrolled students in the People section. Selecting the icon with three horizontal lines at the top left allows students to return to the initial page showing all courses available (Figure 4). 
$\equiv$ MANAgement SANITARIO BIOETICA E DEONTOL...

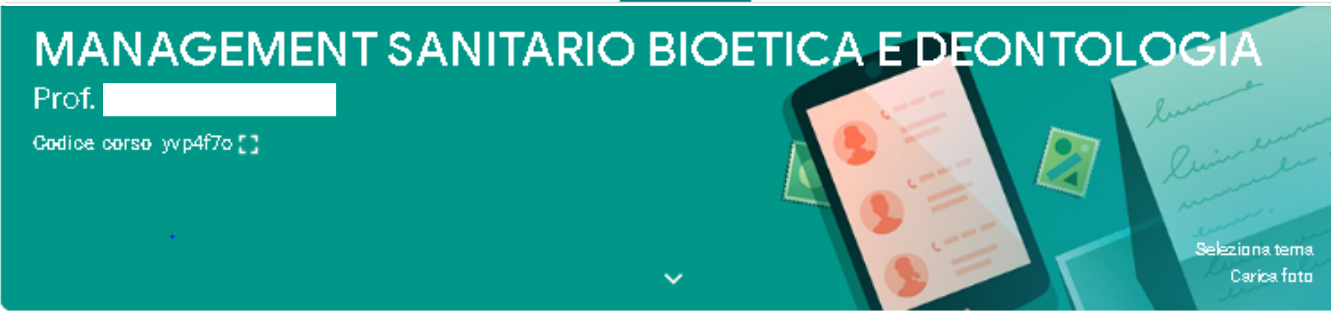

Nessun kavara in scadenza a breve

Visualizza tutto

$23 \mathrm{mar}$

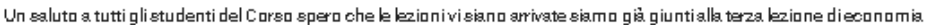
sziendake. Vis augura un buan percarsa dispprendimenta resa purtroppo camplicata dallsattuale situszione d'emergenza. Buan kavara! Giancarla David

Leziani 1-2-3 Econamiz Aziendale del 06/3-13/03-20/3

Figure 3. Classroom interface for course work

$\equiv$ GoogleClassroom

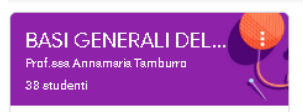

Scadenza Iuned

Scadenzz: lunedi
14:00 - Depliant norme antilussazilione prote.
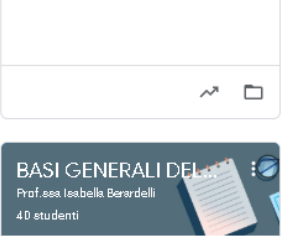

$\leadsto \square$
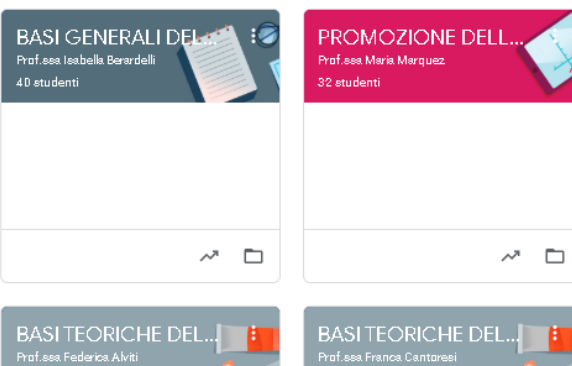
Prot sesa Federisa Ah

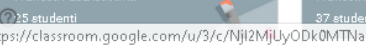

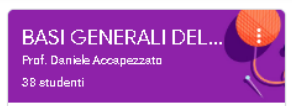

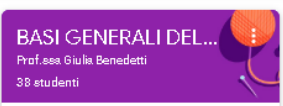

38 studenti
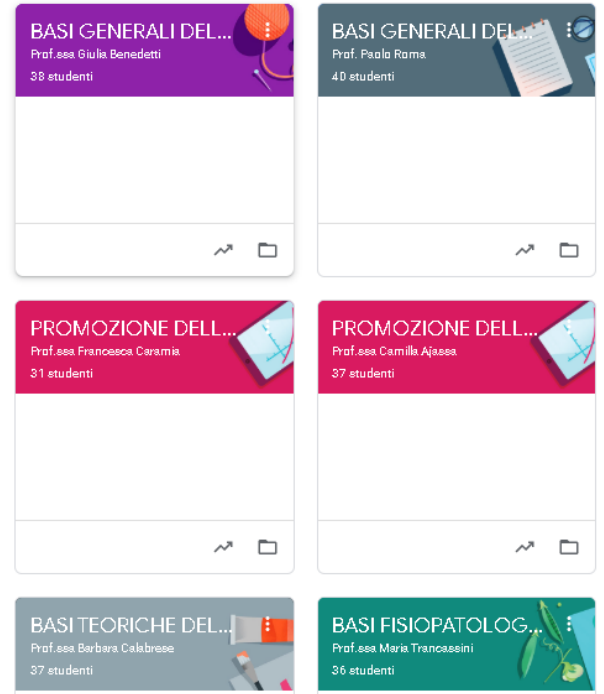
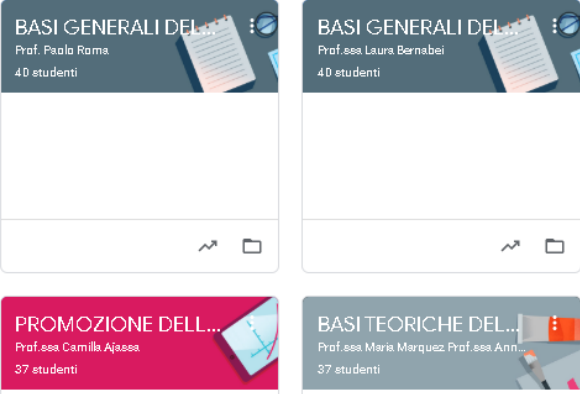

In scadenzadamani
23:59 - Campitto 21/04/2020
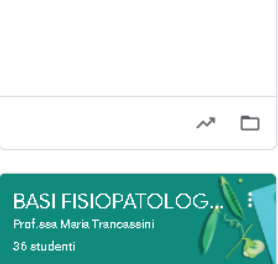

BASI FISIOPATOLOG.

37 studenti

Figure 4. Classroom homepage listing all courses 
Phase 2 - Publication on the teacher's webpage

Once the virtual classroom has been activated, the teacher must notify the students on the notice board of the teacher card in the Study Program Catalog, and then specify the platform used and the link or code of the online course.

Phase 3 - Teaching provision

To provide distance teaching, the teacher can use one of the methods described below.

1) Off-line mode: The teacher prepares and loads the lesson with recorded audio using the IT tools made available by the university or other options of the teacher's choice. The recording of the lesson must contain the explanation by the teacher in audio format. In the event that the teacher has difficulty in realizing a lesson with recorded audio, text must be made available that completely replaces the content from and the duration of the audio recording.

2) Online mode: The teacher delivers the lesson via streaming or video conferencing at a time agreed upon by the students. The communication of the timetable and methods to students is facilitated through the virtual classroom. Upon starting the online delivery of the lesson, the teacher activates the video call recording mode to record the lesson.

The Meet functionality of Google was chosen by Sapienza University's degree courses in the rehabilitation sciences program as the software for the realization of remote lessons, receptions and webinars. This tool allows several people to connect remotely through video lessons, receptions and meetings. It facilitates communication via chat and video conference capabilities with useful accessibility tools, such as automatic subtitles. To cope with the COVID-19 emergency, until 1 July 2020, Google has made available to all schools that use G Suite for Education some advanced Meet features, such as making video calls with up to 250 participants and the possibility of saving recorded meetings on Google Drive (live streaming).

To use the Meet tool, it is necessary to first access the @ uniroma1 university mailbox, and then select the square Meet icon from the icon menu in the mailbox. The main screen of the application is presented (as shown in Figure 5) and the user can select 'Join a meeting' to begin. At the end of the lesson, the teacher loads the registration inside the activated teacher-student work environment.

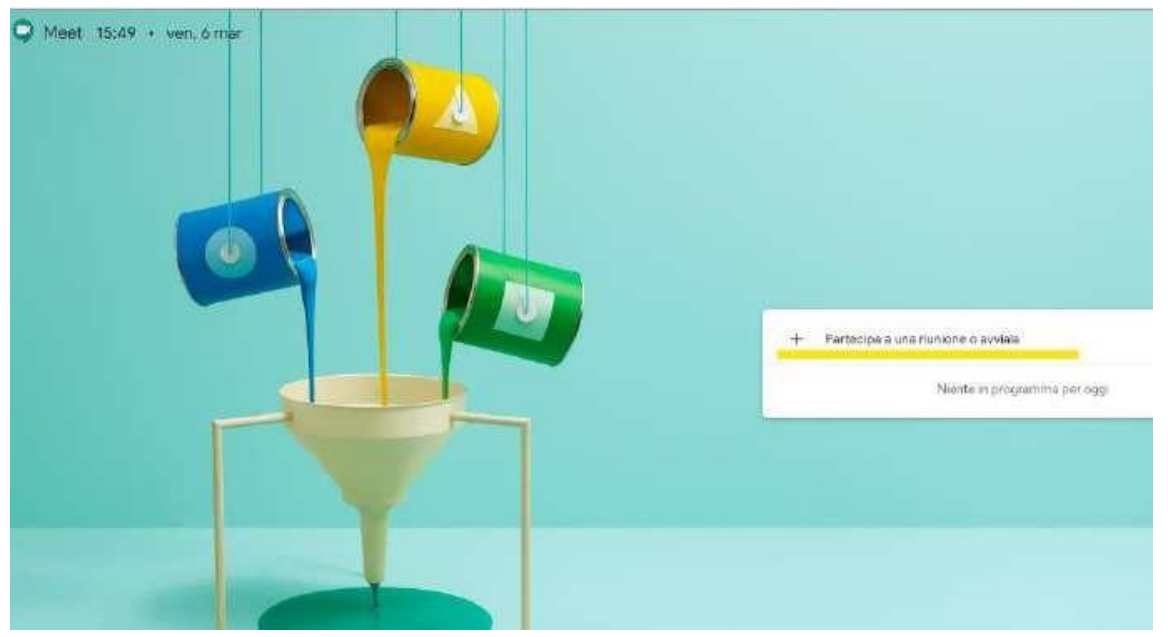

Figure 5. Google Meet Homepage

\section{CONCLUSION}

By March 11, 2020, all courses were created and access codes communicated to students. To date, several students are successfully attending the courses. From preliminary opinions collected, students have already expressed positive feedback regarding the quality of the content and the methods of lesson delivery. It would be beneficial to confirm this response by conducting an in-depth investigation in the coming months. Although the data available was minimal by coming from one program at the university, the results are positive, effective and worthy of being shared with other disciplines. The authors of this study believe that sharing their 
experiences is extremely important and necessary given the challenging and incredible circumstances of emergency response that universities are facing. It is the wish of the authors that academic experts will be encouraged to share strategies being used to address the challenges that threaten the high educational standards of universities around the world.

\section{REFERENCES}

Decree of the President of the Council of Ministers of March 4, 2020. Available at: http://www.governo.it/sites/new.governo.it/files/DPCM4MARZO2020.pdf (Accessed: 29 April 2020).

Electronic Platform for Adult Learning in Europe. COVID-19 is reviving the need to explore online teaching and learning opportunities. 24 March 2020. Available at: https://epale.ec.europa.eu/en/blog/covid-19-reviving-need-explore-onlineteaching-and-learning-opportunities (Accessed: 29 April 2020) World Health Organization, Coronavirus disease 2019 (COVID-19) Situation Report 46, 2020.

Jones S. Covid-19 is our best chance to change universities for good. The Guardian. 31 Mar 2020. Available at: https://www.theguardian.com/education/2020/mar/31/covid-19-is-our-best-chance-to-change-universities-for-good. (Accessed: 29 April 2020).

Farina I. et al, 2019. High-Fidelity Simulation Type Technique Efficient for Learning Nursing Disciplines in the Courses of Study: An Integrative Review. In: Methodologies and Intelligent Systems for Technology Enhanced Learning, 9th International Conference, Workshops. Avila, Spain

Galeoto G. et al, 2019 a. The Use of a Dedicated Platform to Evaluate Health-Professions University Courses. In book: Methodologies and Intelligent Systems for Technology Enhanced Learning, 8th International Conference. Toledo, Spain.

Galeoto G. et al, 2019 b. Evaluation of the Disciplinary Competences of the Students of the Bachelor's Degree in Physiotherapy at "Sapienza" University of Rome Through the TECO: A Cross-Sectional Study. In book: Learning Technology for Education Challenges. Zamora, Spain.

Paterniani A. et al, 2019. Electronic Test of Competence Administration: Qualitative Evaluation of Students' Satisfaction on Telematic Platform a Cross Sectional Study. In: Methodologies and Intelligent Systems for Technology Enhanced Learning, 9th International Conference, Workshops. Avila, Spain

The United Nations Educational, Scientific and Cultural Organization (UNESCO) a. COVID-19 Educational Disruption and Response. Available at: https://en.unesco.org/covid19/educationresponse (Accessed: 29 April 2020).

The United Nations Educational, Scientific and Cultural Organization (UNESCO) b. Distance learning solutions. 2020. Available at: https://en.unesco.org/covid19/educationresponse/solutions (Accessed: 29 April 2020) 